\title{
DISTRIBUTION AND EXCRETION OF FOUR TETRACYCLINE ANALOGUES IN NORMAL YOUNG MEN *
}

\author{
By CALVIN M. KUNIN, $\dagger$ A. C. DORNBUSH aNd MAXWELL FINLAND
}

(From the Thorndike Memorial Laboratory, Second and Fourth (Harvard) Medical Services,
Boston City Hospital, and the Department of Medicine, Harvard Medical School,
Boston, Mass., and from the Biochemical Research Section, Lederle Labora-
tories Division, American Cyanamid Company, Pearl River, N. Y.)

(Submitted for publication June 23, 1959; accepted July 10, 1959)

Three tetracycline analogues, tetracycline (TC), chlortetracycline (CTC) and oxytetracycline (OTC) have been used extensively in man and are well established as effective antimicrobial agents. Recently a fourth analogue, demethylchlortetracycline (DMCT) was described (1) and is being introduced for clinical use. ${ }^{1}$ The structural formulas of these four tetracyclines are shown in Figure 1. Some of the important properties of the new analogue are: its resistance to heat, stability in acid and alkaline solution (1), good absorption with well-sustained blood levels (2-4) and antibacterial activity comparable to the best of the previously available analogues (1-5) and, in many instances, superior to them (5). The half-life of DMCT in serum following an oral dose was found to be 44 per cent longer than that of TC; this was shown to be related to the slower rate of renal excretion of the former (2). Thus, DMCT was shown to produce much higher and better sustained levels of antibacterial activity in the serum than either TC $(2,3)$, CTC $(3,4)$ or OTC (4).

The antibacterial spectra of the first three tetracyclines have been found to be identical, although some differences in their relative activity against certain organisms have been noted (5-12); the same is true for DMCT (5). An appreciation of the differences among the tetracyclines with respect to activity, physical properties, stability, solubility, plasma protein binding and absorption, distribution and excretion in vivo and toxicity should help to determine which, if any, may be

* Aided in part by Research Grant E-23 from the National Institutes of Health, Bethesda, Md.

$\dagger$ Postdoctoral Fellow of the National Institute of A1lergy and Infectious Diseases. Present address: Department of Preventive Medicine, University of Virginia, Charlottesville, Va.

1 Under the trademark Declomycin $\circledast$. superior for any particular clinical situation. The present report presents a comparison of the distribution and excretion of the four analogues as observed in the same four healthy young men following single intravenous injection of each of them. The binding of these analogues to plasma protein was also determined in vitro.

\section{MATERIALS AND METHODS}

Tetracycline analogues. Sterile ampules labeled as containing $500 \mathrm{mg}$. of the hydrochloride of TC and CTC and $250 \mathrm{mg}$. of DMCT-HCl were provided by Lederle Laboratories Division of American Cyanamid Co., and similar ampules of OTC- $\mathrm{HCl}$, labeled as containing 500 mg. base equivalent, were furnished by Charles Pfizer and Co. Each of these preparations was buffered with ascorbic acid except the CTC which was buffered with sodium glycinate. Crystalline preparations of each of the analogues were also made available for standard solutions and for studies of plasma protein binding. For intravenous injection, each dose was dissolved in $150 \mathrm{ml}$. of 5 per cent aqueous solution of dextrose and given over a period of 15 to 20 minutes. Two ampules of each of the lots used were assayed for total drug content and the results are shown in Table I. In the text and tables that follow, the doses given refer to the labeled potency, but all calculations and comparisons of distribution and excretion are based on the assayed values.

Subjects and design of study. Four healthy young men, ranging in age from 28 to 32 years and in weight from 68 to $71 \mathrm{Kg}$., were given each of the drugs intravenously in the following sequence: TC, $500 \mathrm{mg}$.; CTC, $500 \mathrm{mg}$.; OTC, $500 \mathrm{mg}$.; DMCT, $250 \mathrm{mg}$. and DMCT, $500 \mathrm{mg}$. The individual doses were separated by intervals of one to two weeks in order to insure complete elimination before the next dose was given. Blood specimens were obtained before and at 30 minutes after completion of the injections, at the midpoint of three sequential 30 minute urine collections begun two hours after completion of the injection, and at 4, 6, 8, 12, 24 and 30 hours. The serums were separated as soon as possible and stored at $-20^{\circ} \mathrm{C}$. until the time of the assays.

All urine excreted during the 96 hours after the beginning of the injection was collected. During each col- 
<smiles>CC(C)C1C2C(=C(O)C3(O)C(=O)C(N(C)C)C(O)(O)C13)C(=O)c1c(O)ccc(Cl)c1C2(C)O</smiles>

CHLORTETRACYCLINE<smiles></smiles>

TETRACYCLINE

Fig. 1. Structural Formulas of

lection period, the specimens were refrigerated at $4^{\circ} \mathrm{C}$; at the end of each period these were pooled and aliquots were removed and stored at $-20^{\circ} \mathrm{C}$. until the time of the assays. Except for the initial two hour period and the three 30 minute periods of the clearance studies, all urines collected from each subject during each 24 hour period were pooled into a single specimen.

Assays of tetracycline analogues. Assays for antibiotic activity in serum were performed by the cup-plate method using Bacillus cereus var. mycoides ATCC 9634 as test organism (13); the antibiotic content of urine was assayed by the turbidimetric method using Staphylococcus aureus ATCC 6538-P (13). Results of each assay were recorded as the mean of two separate determinations done on each specimen, and standard solutions of all four analogues were included with each assay. All assays were carried out in the Research Laboratories of American Cyanamid Co. to which the specimens were delivered in the frozen state under code designations.

Renal clearance. The subjects were given adequate fluids during the first four hours of each study in order to maintain a urine flow of 4 to $12 \mathrm{ml}$. per minute. Beginning two hours after the end of the injection, three sequential 30 minute urine collections were made without catheterization and blood samples were drawn midway in each period. One of these blood specimens and an aliquot of urine were analyzed for creatinine content 2 by a modification of the method of Bonsnes and Taussky (14).

Calculations. Renal clearance (C) of antibiotic $\left(\mathrm{C}_{\mathrm{ar}}\right)$ or of creatinine ( $C_{\text {creat }}$ ) was calculated from the stand-

\footnotetext{
2 Carried out by Miss Ellen J. Doyle.
}

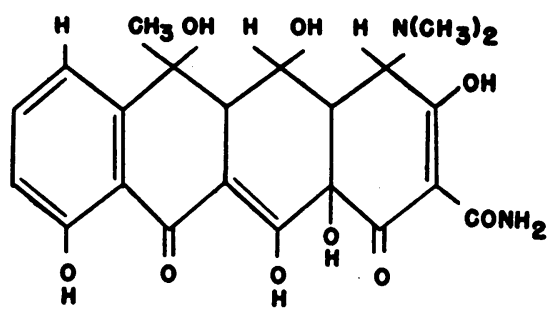

OXYTETRACYCLINE

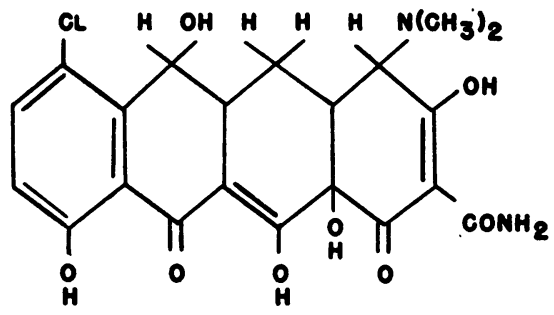

DEMETHYLCHLORTETRACYCLINE

Four Tetracycline Analogues

ard formula (15). Standard deviation (S. D.) was calculated from the values for each of the 30 minute periods (16).

When the concentrations of antibiotic in the serum following intravenous injection were plotted on semilogarithmic paper, two rates of decline were noted: an initial rapid fall followed by a slower one. The second slope

TABLE I

Results of assays of tetracycline analogues used for intravenous injection in this study*

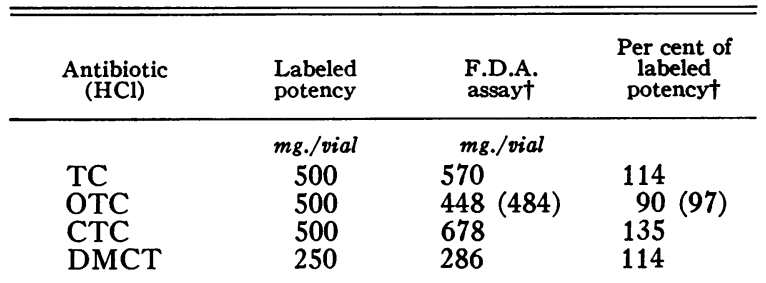

* TC = tetracycline; $\quad$ OTC $=$ oxytetracycline; $\quad$ CTC = chlortetracycline; DMCT =demethylchlortetracycline.

$\dagger$ Assays were performed by the Staphylococcus aureus turbidimetric method in the Antibiotics Division, Food and Drug Administration, through the courtesy of Dr. Henry Welch and Dr. William W. Wright. Both labeled and assayed values were calculated as hydrochloride except those for OTC which are given in terms of the base; values for the corresponding hydrochloride of OTC are given in parentheses.

The values are given in terms of the same antibiotic. Comparisons of the activity of the standard solutions of the four antibiotics indicated that, on a weight basis, DMCT was 90 per cent as active as CTC, 1.9 times as active as OTC and three times as active as TC against the assay organism, Staphylococcus aureus ATCC 6539P. 
(k) was calculated by the method of least squares (2) and the half-life of the antibiotic in the serum $\left(T_{s} / 2\right)$, expressed in hours, was then calculated.

Rate of decline in the concentration of antibiotic in serum $\left(K_{s}\right)$ was expressed as per cent per hour:

$$
\mathrm{K}_{\mathrm{s}}=\frac{0.693}{T_{\mathrm{s}} / 2} \times 100 .
$$

Relative volume of distribution (RVD) was expressed in liters:

$$
\mathrm{RVD}=\frac{\mathrm{mg} . \text { injected }^{3}}{\mathrm{C}_{0}}
$$

where $C_{0}$ equals the expected concentration, in micrograms of antibiotic per milliliter of serum immediately after completion of the injection, assuming instantaneous mixture, and determined from the second or slow decline of antibiotic in serum.

${ }^{3}$ Based on the assays shown in Table I.
The per cent volume distribution per $\mathrm{Kg}$. body weight was calculated as:

$$
\frac{\text { RVD }}{\mathrm{Kg} \text {. body weight }} \times 100 \text {. }
$$

Clearance of antibiotic from serum $\left(\mathrm{C}_{\mathbf{a s}}\right)$ was given in milliliters per minute:

$$
\mathrm{C}_{\mathrm{as}}=\frac{\mathrm{K}_{\mathrm{s}} \times \mathrm{RVD} \times 1,000}{60} .
$$

The expected (calculated) urinary recovery $\left(R_{c}\right)$ of antibiotic was expressed in per cent of the actual amount administered :

$$
\mathrm{R}_{\mathrm{c}}=\frac{\mathrm{C}_{\mathrm{ar}}}{\mathrm{C}_{\mathrm{as}}} \times 100 .
$$

The rate of removal by the kidney $\left(\mathrm{K}_{\mathbf{r}}\right)$ was expressed as per cent extracted per hour:

$$
\mathrm{K}_{\mathrm{r}}=\frac{\mathrm{C}_{\mathrm{ar}} \times 60}{\mathrm{RVD} \times 1,000} \times 100 .
$$
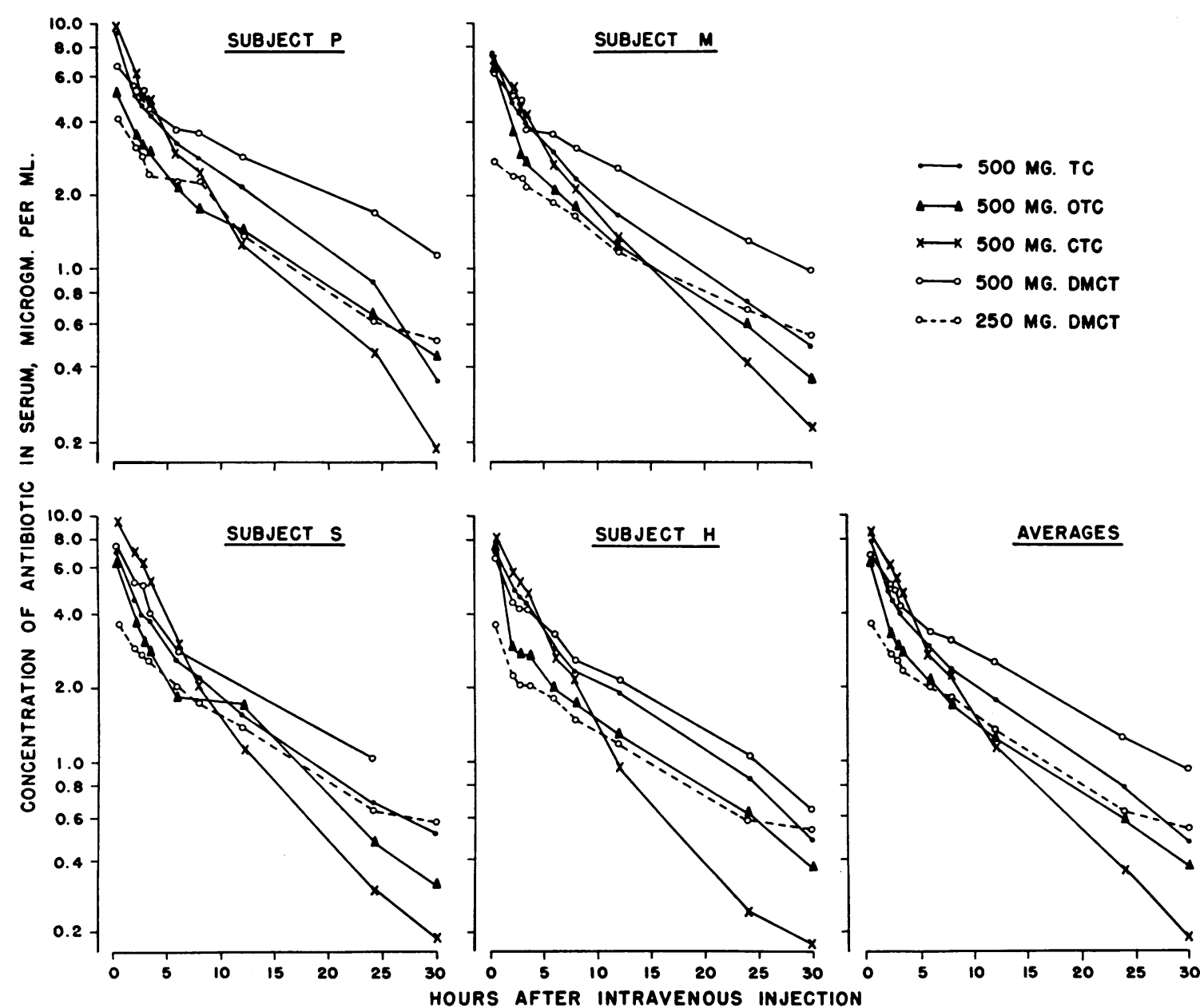

Fig. 2. Concentrations of Four Tetracycline Antibiotics in Serum of Four Normal Men After Single Intravenous InJeCtions

The levels are plotted on a logarithmic scale and are given in terms of the antibiotic that was administered. 
TABLE II

Disappearance of four tetracycline analogues from serum after single intravenous injections*

\begin{tabular}{|c|c|c|c|c|c|c|c|c|c|c|c|c|}
\hline \multirow[b]{2}{*}{ Subject } & \multirow[b]{2}{*}{ Weight } & \multirow[b]{2}{*}{ Height } & \multicolumn{5}{|c|}{ Rate of decay in serum $\left(\mathrm{K}_{\mathrm{s}}\right)$} & \multicolumn{5}{|c|}{ Half-life in serum $\left(T_{8} / 2\right)$} \\
\hline & & & TC & OTC & CTC & DMCT & $\mathrm{DMCT}_{250}$ & $\mathrm{TC}$ & OTC & CTC & DMCT & $\mathrm{DMCT}_{250}$ \\
\hline $\begin{array}{c}\mathrm{H} \\
\mathrm{M} \\
\mathrm{P} \\
\mathrm{S} \\
\text { Mean }\end{array}$ & $\begin{array}{l}K g . \\
68.0 \\
70.5 \\
61.5 \\
71.0 \\
67.8\end{array}$ & $\begin{array}{l}c m . \\
177 \\
170 \\
177 \\
186 \\
178\end{array}$ & $\begin{array}{c}\% / h r . \\
7.9 \\
8.2 \\
9.1 \\
7.2 \\
8.2\end{array}$ & $\begin{array}{c}\% / h r . \\
7.3 \\
7.7 \\
7.2 \\
8.1 \\
7.6\end{array}$ & $\begin{array}{c}\% / h r . \\
13.5 \\
11.0 \\
11.3 \\
13.9 \\
.12 .4\end{array}$ & $\begin{array}{c}\% / h r . \\
6.2 \\
5.2 \\
4.9 \\
5.7 \\
5.5\end{array}$ & $\begin{array}{c}\% / h r . \\
5.4 \\
5.6 \\
6.6 \\
6.2 \\
6.0\end{array}$ & $\begin{array}{l}\text { hrs. } \\
8.8 \\
8.4 \\
7.6 \\
9.1 \\
8.5\end{array}$ & $\begin{array}{l}\text { hrs. } \\
9.5 \\
9.1 \\
9.6 \\
8.5 \\
9.2\end{array}$ & $\begin{array}{l}\text { hrs. } \\
5.1 \\
6.3 \\
6.1 \\
5.0 \\
5.6\end{array}$ & $\begin{array}{c}\text { hrs. } \\
11.2 \\
13.3 \\
14.1 \\
12.1 \\
12.7\end{array}$ & $\begin{array}{c}\text { hrs. } \\
12.9 \\
12.4 \\
10.5 \\
11.2 \\
11.8\end{array}$ \\
\hline
\end{tabular}

* TC $=$ tetracycline $;$ OTC $=$ oxytetracycline $; \mathrm{CTC}=$ chlortetracycline $; \mathrm{DMCT}=$ demethylchlortetracycline. Each was given in a dose (labeled) of $500 \mathrm{mg}$., except for the $250 \mathrm{mg}$. dose designated $\mathrm{DMCT}_{250}$.

The nonrenal removal rate $\left(\mathrm{K}_{\mathrm{nr}}\right)$ was expressed in per cent per hour :

$$
K_{n r}=K_{s}-K_{r}
$$

Plasma binding. Dialysis equilibrium studies were performed twice with each of the four analogues. The hydrochloride was used both times except for OTC, of which the base was employed on the first occasion. A 0.1 per cent aqueous solution of each drug was diluted

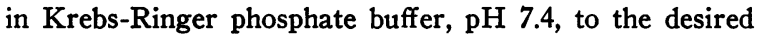
concentrations, namely 5, 12 and $20 \mu \mathrm{g}$. per $\mathrm{ml}$. Five $\mathrm{ml}$. amounts of normal human plasma were placed in cellophane bags (Nojax Casing No. 24, Visking Corporation), which were sealed and placed, in duplicate, each into a sterile screw-capped tube containing $5 \mathrm{ml}$. of antibiotic diluted in the Krebs-Ringer phosphate buffer. The tubes were placed in a mechanical device at $4^{\circ} \mathrm{C}$. and rocked 18 times per minute. The contents of one set of bag and bath fluids were harvested at 24 hours and those of the other at 48 hours and promptly stored at $-20^{\circ} \mathrm{C}$. until they were assayed. Before the assays, the specimens were diluted and adjusted, when necessary, to achieve uniform protein content and $\mathrm{pH}$ among the specimens and standard controls. Two sets of control tubes, in which buffer was substituted for plasma in the bag and $10 \mu \mathrm{g}$. of antibiotic per $\mathrm{ml}$. placed in the bath, were run during the second experiment.

Plasma protein binding, expressed in per cent, was determined by the formula :

Per cent bound

$$
=\frac{\text { concentration in plasma }- \text { concentration in bath }}{\text { concentration in plasma }}
$$

RESULTS

\section{Concentrations of antibiotics in serum}

Figure 2 shows the levels of each antibiotic in serum at intervals after the intravenous injections of $500 \mathrm{mg}$. of the four tetracycline analogues and after the $250 \mathrm{mg}$. dose of DMCT for each subject; the mean values for all subjects are also charted.
The initial rapid decline, representing distribution into various body compartments, was complete by two to three hours after the injection of each drug. Comparisons of the second or slower rate of decline indicate that the levels of CTC in the serum fell more rapidly than those of the other analogues; the levels of TC and OTC fell at intermediate rates, while the slowest decline was for both dose levels of DMCT. This was true of the values for each individual and of the mean for all four subjects.

Decay rates and half-lives of the antibiotics in the serum, calculated from these data, are given in Table II. CTC was removed from serum most rapidly, at an average rate of 12.4 per cent per hour; TC and OTC decayed at similar and intermediate rates, averaging 8.2 and 7.6 per cent per hour, respectively, and DMCT showed the slowest decay, namely, 6.0 and 5.5 per cent per hour after the $250 \mathrm{mg}$. and $500 \mathrm{mg}$. doses, respectively. Correspondingly, the shortest average half-life was 5.6 hours for CTC; the half-lives of TC and OTC were intermediate at 8.5 and 9.2 hours, respectively, while that of DMCT was the longest, namely, 11.8 and 12.7 hours after the 250 and 500 mg. doses, respectively. Although there were some variations among the different subjects in the half-life of these antibiotics, each analogue was found to have a distinct rate of decay in serum, within fairly narrow limits.

\section{Relative distribution volumes}

The calculated values for the RDV of the four analogues are given in Table III; these all show distributions greater than the total body weight, presumably due to sequestrations in certain organs such as the liver and reticuloendothelial system 
TABLE III

Relative volume distribution (RDV) of four tetracycline analogues after single intravenous injection*

\begin{tabular}{|c|c|c|c|c|c|c|c|c|c|c|}
\hline \multirow[b]{2}{*}{ Subject } & \multicolumn{5}{|c|}{ RDV } & \multicolumn{5}{|c|}{ Per cent RDV per $\mathrm{Kg}$. body weight } \\
\hline & TC & OTC & CTC & DMCT & $\overline{D_{M C T} 250}$ & TC & OTC & CTC & DMCT & $\mathrm{DMCT}_{200}$ \\
\hline $\begin{array}{c}\mathbf{H} \\
\mathbf{M} \\
\mathbf{P} \\
\stackrel{\mathbf{S}}{\text { Mean }}\end{array}$ & \begin{tabular}{r}
\multicolumn{1}{c}{$L}$. \\
109.6 \\
110.3 \\
122.1 \\
90.8 \\
108.2
\end{tabular} & $\begin{array}{c}L . \\
130.5 \\
128.2 \\
121.3 \\
132.0 \\
128.0\end{array}$ & \begin{tabular}{r}
\multicolumn{1}{c}{$L}$. \\
99.9 \\
120.1 \\
98.6 \\
81.5 \\
100.0
\end{tabular} & $\begin{array}{c}L . \\
118.8 \\
122.9 \\
108.1 \\
134.1 \\
121.0\end{array}$ & \begin{tabular}{r}
\multicolumn{1}{c}{$L}$. \\
119.3 \\
107.6 \\
83.2 \\
92.0 \\
100.5
\end{tabular} & $\begin{array}{l}161 \\
156 \\
172 \\
148 \\
159\end{array}$ & $\begin{array}{l}192 \\
182 \\
187 \\
186 \\
189\end{array}$ & $\begin{array}{l}147 \\
170 \\
160 \\
115 \\
148\end{array}$ & $\begin{array}{l}175 \\
174 \\
176 \\
189 \\
179\end{array}$ & $\begin{array}{l}175 \\
153 \\
135 \\
130 \\
148\end{array}$ \\
\hline
\end{tabular}

* See footnote, Table II.

(17-20). The largest RDV was that of OTC; this averaged 189 per cent of the body weight. The two doses of DMCT yielded different average values, ${ }^{4}$ the larger (179 per cent for the $500 \mathrm{mg}$. dose) approximating that of OTC. The smaller dose of DMCT gave an average value similar to those calculated for TC and CTC, each being about 150 per cent of the body weight. There were considerable individual variations in the values among the subjects, ${ }^{4}$ the smallest differences being noted with OTC.

\section{Rates of clearance from serum}

The rate of clearance of each of the four tetracycline anologues from serum, as calculated from the rate of decline of its concentration in serum and its RDV, is shown in Table IV. CTC was cleared at a much more rapid rate (more then $200 \mathrm{ml}$. per minute) than the other analogues and about twice as rapidly as DMCT; OTC and TC were cleared at similar rates that were intermediate between those of CTC and DMCT. The slightly

TABLE IV

Clearance of four tetracycline analogues from serum after a single intravenous injection*

\begin{tabular}{cccccc}
\hline \hline & \multicolumn{5}{c}{ Clearance from serum } \\
\cline { 2 - 6 } Subject & TC & OTC & CTC & DMCT & DMCT 260 \\
\hline & ml./min. & mb./min. & ml./min. & ml./min. & ml./min. \\
H & 145 & 159 & 225 & 123 & 107 \\
M & 151 & 164 & 219 & 107 & 100 \\
P & 185 & 146 & 186 & 89 & 92 \\
S & 116 & 179 & 189 & 128 & 95 \\
Mean & 149 & 162 & 205 & 112 & 99
\end{tabular}

* See footnote, Table II.

4 Presumably related in part, at least, to differences in time required for complete mixing and equilibration in the body compartments. more rapid decay of TC in serum in spite of its slower clearance from serum as compared with that of OTC (Table II) will be shown to be due to the more rapid renal clearance of the latter.

\section{Renal clearances}

The calculated renal clearances per $1.73 \mathrm{M.}^{2}$ of body surface for each of the four tetracyclines and for creatinine are shown together with the ratio of these values in Table V. There were wide variations in the simultaneously performed creatinine clearances, ${ }^{5}$ but each of the four tetracycline analogues was cleared at a fairly distinct rate, with only minor individual variations considering the small number of observations (12 for each mean value). OTC was the most rapidly cleared by the kidney ( $85 \pm 14$ per cent of the creatinine clearance); CTC and DMCT were each cleared at approximately the same rate, namely, about 30 per cent of that of creatinine, and TC was cleared

TABLE V

Renal clearance of four tetracycline analogues compared with simultaneous creatinine clearance in four healthy young men*

\begin{tabular}{|c|c|c|c|}
\hline \multirow[b]{2}{*}{ Antibiotic } & \multicolumn{2}{|c|}{ Renal clearance } & \multirow[b]{2}{*}{$\frac{C_{a r}}{C_{\text {cereat }}}$} \\
\hline & $\begin{array}{c}\text { Antibiotic } \\
\left(\mathrm{C}_{\text {ar }}\right)\end{array}$ & $\begin{array}{c}\text { Creatinine } \\
\left(\mathrm{C}_{\text {croat }}\right)\end{array}$ & \\
\hline $\begin{array}{l}\text { TC } \\
\text { OTC } \\
\text { CTC } \\
\text { DMCT }_{\text {DMCT }_{250}}\end{array}$ & $\begin{array}{r}\operatorname{ml} . / \min . \\
73.5 \pm 7.8 \\
98.6 \pm 5.7 \\
32.1 \pm 8.0 \\
35.2 \pm 6.7 \\
35.3 \pm 7.9\end{array}$ & $\begin{array}{l}3 M .^{2} \pm S . D . \\
120.6 \pm 21.3 \\
115.6 \pm 16.5 \\
108.3 \pm 8.7 \\
131.2 \pm 41 \\
111.9 \pm 41\end{array}$ & $\begin{array}{l}\% \pm S . D . \\
62 \pm 8 \\
85 \pm 14 \\
30 \pm 8 \\
27 \pm 8 \\
32 \pm 16\end{array}$ \\
\hline
\end{tabular}

* See footnote, Table II.

5 This was probably related to discrepancies in the timing of the urine collections. However, the means of creatinine clearances for any one individual were reproducible within much narrower limits. 
at an intermediate rate, which was $62 \pm 8$ per cent of the creatinine clearance. The rate of renal clearance of each of the four analogues was independent of the rate of urine flow, as shown in Figure 3.

\section{Urinary recoveries}

The cumulative urinary excretion of each of the tetracycline analogues over a period of four days after the single intravenous dose is depicted in Figure 4. The per cent recovered was calculated on the basis of the assayed values of the administered doses, as shown in Table I. Almost all of the amounts excreted were recovered in the urine during the first 24 hours, but small amounts of each were still detected on the fourth day, except for CTC which could not be detected in urine after the third day. The most rapidly and completely excreted analogue was OTC; TC ranked next in these respects, followed by DMCT and CTC.

Figure 5 presents a comparison of the expected total urinary recovery of each analogue (as calculated from the ratio of the renal clearance to the clearance from serum) and the assayed amounts actually recovered. In each instance, the amount recovered was somewhat greater than the expected or calculated amount, but the corresponding values were in close agreement. The differences could have been due to either the errors in the assays, underestimation of the renal clearances or overestimations of the serum clearance rates.

The average per cent of the administered dose that was accounted for in the urine was: 70 per cent for OTC, 60 per cent for TC, 42 per cent for the two doses of DMCT and 18 per cent for CTC.

\section{Rates of renal and nonrenal removal}

The nonrenal removal rates, determined by subtracting the renal removal rates from the serum removal rates and expressed both in per cent removed per hour and as half-life, are presented in Table VI; the calculated renal removal rates, expressed in the same manner are also given. The latter rates, as expected, were more rapid for OT and OTC than for CTC and DMCT. Of par-

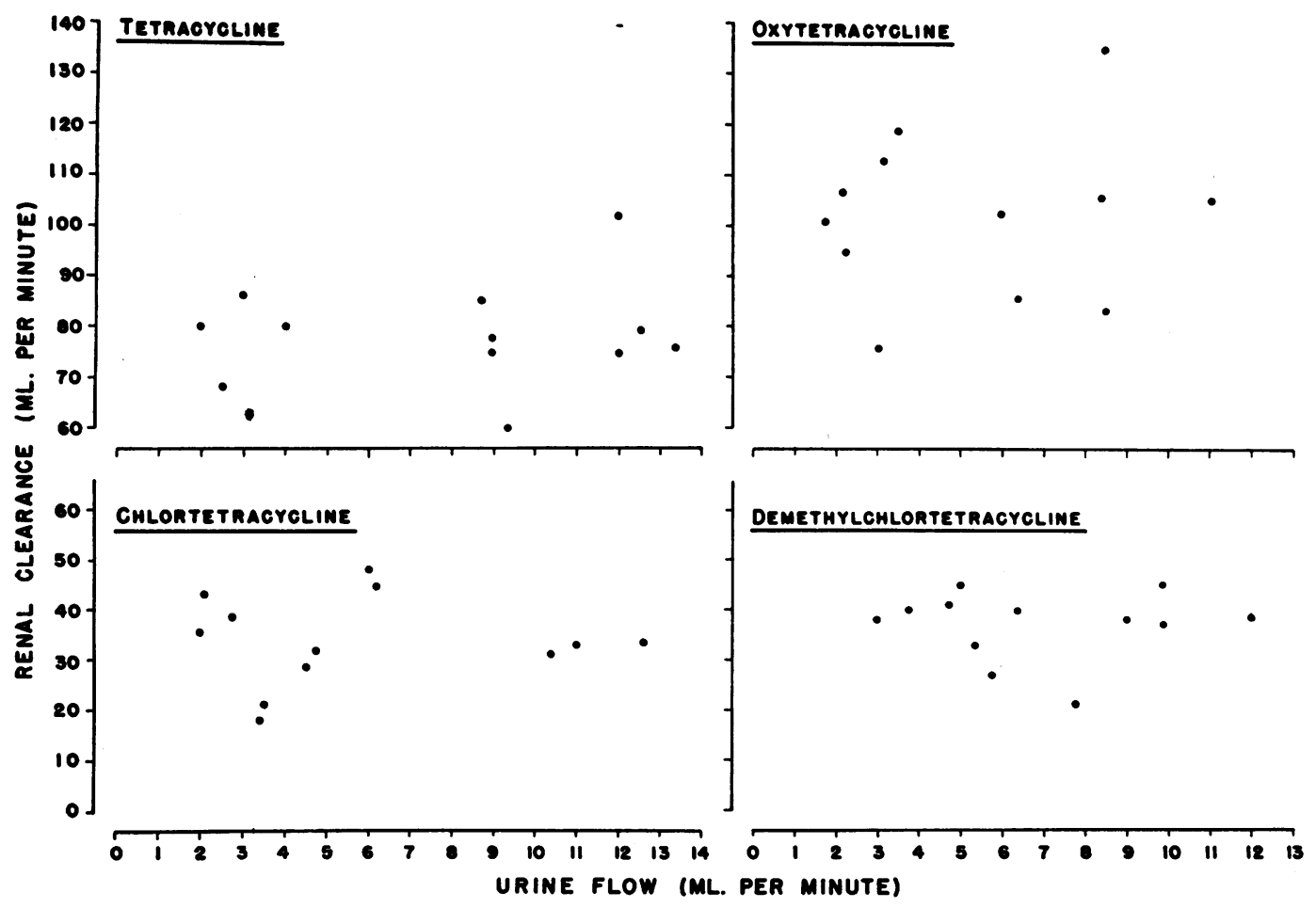

Fig. 3. Correlation of Rates of Renal Clearance of Four Tetracychine Analogues and RATES OF URINe Flow 


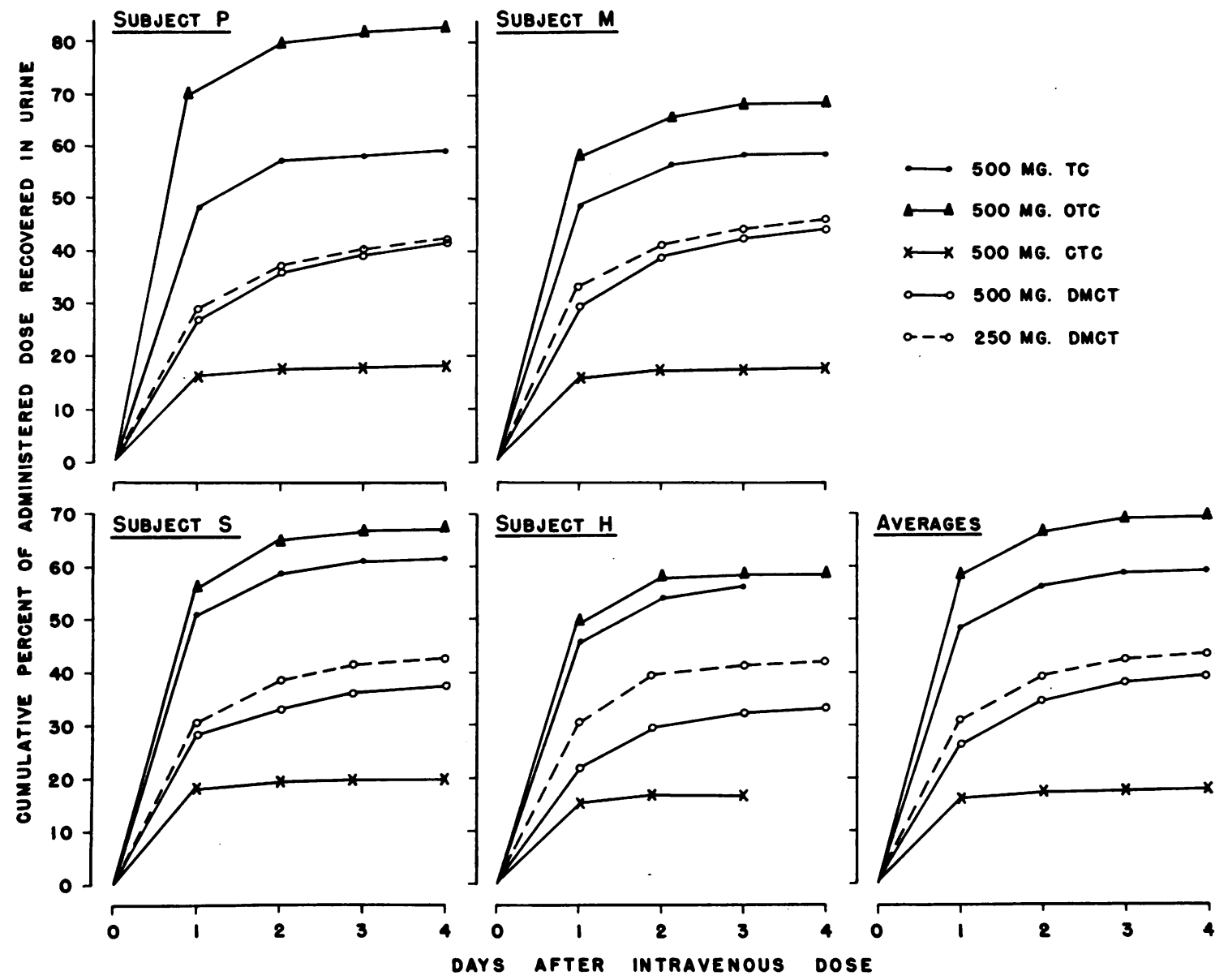

Fig. 4. Cumulative Per Cent of Administered Antibiotics Recovered in the Urine After Single Intravenous Doses of Four Tetracycline Analogues

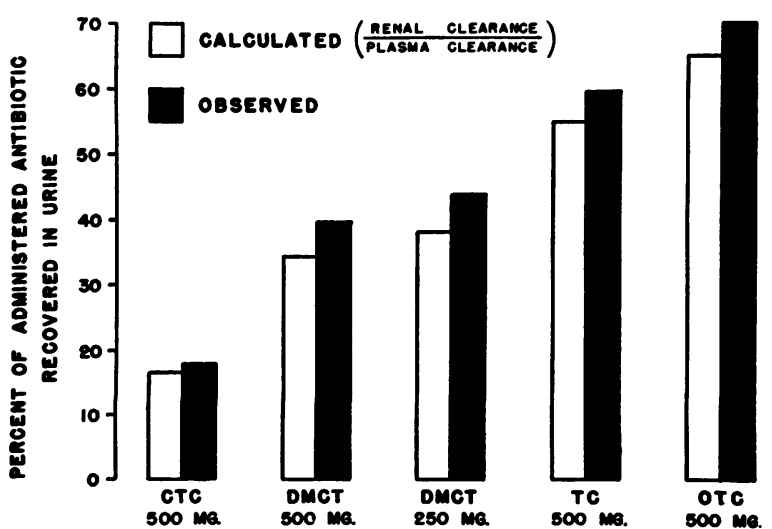

Fig. 5. Comparison of Actual URinary Recoveries of Four Tetracycline Analogues and the Recoveries Expected from Calculations of the Ratio of the Renal Clearance to the Serum Clearance ticular interest, however, is the observation that, except for CTC, the nonrenal removal rates were very similar for each of the analogues, namely about 3 to 4 per cent per hour, or at half-life equivalents of about 20 hours. The much more rapid rate of nonrenal removal of CTC thus represents the in vivo counterpart of the rapid decay in activity of $\mathrm{CTC}$ at $37^{\circ} \mathrm{C}$. in aqueous solutions or plasma in vitro $(6,10,20,21)$.

\section{Plasma protein binding}

The results of determinations of plasma binding of the four tetracyclines done by equilibrium dialysis in two separate experiments and expressed as per cent of antibiotic bound after equilibration for 24 and 48 hours are presented in Table VII. 
TABLE VI

Calculated rates of removal of four tetracycline analogues by renal and nonrenal mechanisms after single intravenous injection*

\begin{tabular}{|c|c|c|c|c|c|c|}
\hline Rates† & Subject & $\mathrm{TC}$ & отC & CTC & DMCT & $\mathrm{DMCT}_{250}$ \\
\hline \multirow[t]{2}{*}{$\begin{array}{l}\mathrm{K}_{\mathrm{r}}: \text { Antibiotic removed by } \\
\text { renal mechanisms } \\
\quad \% / h r .\end{array}$} & $\begin{array}{l}\mathrm{H} \\
\mathrm{M} \\
\mathrm{P} \\
\mathrm{S}\end{array}$ & $\begin{array}{l}4.8 \\
4.7 \\
5.1 \\
5.1\end{array}$ & $\begin{array}{l}3.9 \\
4.0 \\
5.5 \\
4.2\end{array}$ & $\begin{array}{l}2.9 \\
2.3 \\
2.1 \\
4.1\end{array}$ & $\begin{array}{l}2.0 \\
2.3 \\
2.4 \\
1.6\end{array}$ & $\begin{array}{l}2.7 \\
2.3 \\
2.7 \\
2.5\end{array}$ \\
\hline & Mean & 4.9 & 4.4 & 2.9 & 2.1 & 2.6 \\
\hline \multirow[t]{2}{*}{$\begin{array}{l}\mathrm{T}_{\mathrm{r}} / 2: \text { Hours required to } \\
\text { remove } 50 \% \text { of the } \\
\text { antibiotic by renal } \\
\text { mechanisms }\end{array}$} & $\begin{array}{l}\mathrm{H} \\
\mathrm{M} \\
\mathrm{P} \\
\mathrm{S}\end{array}$ & $\begin{array}{l}14.3 \\
14.7 \\
13.6 \\
13.6\end{array}$ & $\begin{array}{l}17.6 \\
17.2 \\
12.7 \\
16.6\end{array}$ & $\begin{array}{l}23.9 \\
29.9 \\
32.5 \\
17.1\end{array}$ & $\begin{array}{l}34.7 \\
30.0 \\
28.8 \\
48.4\end{array}$ & $\begin{array}{l}25.7 \\
30.5 \\
25.2 \\
27.2\end{array}$ \\
\hline & Mean & 14.1 & 16.0 & 25.9 & 35.5 & 27.2 \\
\hline \multirow[t]{2}{*}{$\begin{array}{l}\mathrm{K}_{\mathrm{nr}}: \text { Antibiotic removed by } \\
\text { nonrenal mechanisms } \\
\% / h r .\end{array}$} & $\begin{array}{l}\mathrm{H} \\
\mathrm{M} \\
\mathrm{P} \\
\mathrm{S}\end{array}$ & $\begin{array}{l}3.1 \\
3.5 \\
4.0 \\
2.6\end{array}$ & $\begin{array}{l}3.4 \\
3.6 \\
1.8 \\
4.0\end{array}$ & $\begin{array}{r}10.6 \\
8.6 \\
9.0 \\
9.9\end{array}$ & $\begin{array}{l}4.2 \\
2.9 \\
2.5 \\
5.1\end{array}$ & $\begin{array}{l}2.7 \\
3.3 \\
3.9 \\
5.9\end{array}$ \\
\hline & Mean & 3.3 & 3.2 & 9.5 & 3.4 & 4.0 \\
\hline \multirow[t]{2}{*}{$\begin{array}{l}\mathrm{T}_{\mathrm{nr}} / 2: \text { Hours required to } \\
\text { remove } 50 \% \text { of the } \\
\text { antibiotic by nonrenal } \\
\text { mechanisms }\end{array}$} & $\begin{array}{l}\mathrm{H} \\
\mathrm{M} \\
\mathrm{P} \\
\mathrm{S}\end{array}$ & $\begin{array}{l}22.5 \\
19.8 \\
17.4 \\
27.1\end{array}$ & $\begin{array}{l}20.6 \\
19.2 \\
38.7 \\
17.5\end{array}$ & $\begin{array}{l}6.5 \\
8.0 \\
7.7 \\
7.0\end{array}$ & $\begin{array}{l}16.5 \\
23.7 \\
27.4 \\
16.8\end{array}$ & $\begin{array}{l}25.9 \\
20.8 \\
17.9 \\
11.7\end{array}$ \\
\hline & Mean & 21.7 & 24.0 & 7.3 & 20.1 & 19.1 \\
\hline
\end{tabular}

* See footnote, Table II.

† See "Materials and Methods" for formulas from which these rates were calculated.

The initial concentrations in the baths were designed to provide levels of antibiotic in plasma comparable to those achieved with the usual therapeutic doses.

There were considerable differences in the per cent of each drug bound to plasma. This was to be expected from the errors inherent in the microbiological assay, the low concentration of drugs used and the considerable effects of changes in $\mathrm{pH}$ on tetracycline activity. In a control study in which buffer was substituted for plasma in the dialysis bag, the mean differences noted in either direction (i.e., bag to bath or vice versa) was about 11 per cent, suggesting that these data should be interpreted with caution with respect to the absolute values.

TABLE VII

Plasma binding of four tetracycline antibiotics*

\begin{tabular}{|c|c|c|c|c|c|c|c|c|}
\hline \multirow{3}{*}{$\begin{array}{c}\text { Initial } \\
\text { concentration } \\
\text { in bath }\end{array}$} & \multicolumn{8}{|c|}{ Per cent bound to plasma } \\
\hline & \multicolumn{2}{|c|}{$\mathrm{TC}-\mathrm{HCl}$} & \multirow{2}{*}{$\frac{\text { OTC-Base }}{\text { Expt. } 1}$} & \multirow{2}{*}{$\frac{\mathrm{OYC}-\mathrm{HCl}}{\text { Expt. } 2}$} & \multicolumn{2}{|c|}{ CTC-HCl } & \multicolumn{2}{|c|}{ DMCT-HCl } \\
\hline & Expt. 1 & Expt. 2 & & & Expt. 1 & Expt. 2 & Expt. 1 & Expt. 2 \\
\hline$\mu g . / m l$. & \multicolumn{8}{|c|}{24 hours } \\
\hline $\begin{array}{c}5 \\
10 \\
20 \\
\text { Mean }\end{array}$ & $\begin{array}{l}13 \\
25 \\
35 \\
24\end{array}$ & $\begin{array}{l}28 \\
23 \\
10 \\
20\end{array}$ & $\begin{array}{r}11 \\
15 \\
5 \\
10\end{array}$ & $\begin{array}{l}42 \\
34 \\
27 \\
34\end{array}$ & $\begin{array}{l}56 \\
52 \\
54\end{array}$ & $\begin{array}{l}42 \\
35 \\
52 \\
43\end{array}$ & $\begin{array}{l}29 \\
36 \\
42 \\
36\end{array}$ & $\begin{array}{l}37 \\
40 \\
63 \\
47\end{array}$ \\
\hline $\begin{array}{c}5 \\
10 \\
20 \\
\text { Mean }\end{array}$ & $\begin{array}{l}30 \\
24 \\
30 \\
28\end{array}$ & $\begin{array}{l}20 \\
25 \\
28 \\
24\end{array}$ & $\begin{array}{l}12 \\
10 \\
11\end{array}$ & $\begin{array}{l}48 \text { h } \\
17 \\
28 \\
23\end{array}$ & $\begin{array}{l}49 \\
30 \\
46 \\
42\end{array}$ & $\begin{array}{l}36 \\
66 \\
51\end{array}$ & $\begin{array}{l}34 \\
57 \\
52 \\
48\end{array}$ & $\begin{array}{l}38 \\
23 \\
42 \\
34\end{array}$ \\
\hline
\end{tabular}

* $\mathrm{TC}=$ tetracycline $; \mathrm{OTC}=$ oxytetracycline $; \mathrm{CTC}=$ chlortetracycline $; \mathrm{DMCT}=$ demethylchlortetracycline. 
The data do indicate, however, that more of the CTC and DMCT were bound than TC and OTC. The mean per cent of antibiotic bound was 47 per cent for CTC and 41 per cent for DMCT (not significantly different), whereas an average of 24 per cent of TC and 20 per cent of OTC was bound to plasma (this difference, likewise, was not significant). The differences between the results obtained at 24 and 48 hours also are not significant. The greatest discrepancy, however, was in the results obtained with OTC in the two experiments, the base being used in the first and the hydrochloride in the second. The reason for this wide discrepancy is not clear since both samples were greatly diluted in phosphate buffer, $\mathrm{pH}$ 7.4.

\section{DISCUSSION}

The chemical structures of the four tetracycline analogues (Figure 1) differ from one another only in the presence or absence of either chlorine, or a hydroxyl or methyl group in one of the three positions on the "upper tier" of the molecule. These chemical differences are not accompanied by changes in the antibacterial spectrum, although differences in relative activity against certain organisms have been noted (5-12); they are, however, associated with major differences in the physical properties of the analogues. Thus, under physiological conditions of temperature and $\mathrm{pH}$, CTC is rapidly inactivated, whereas the other analogues are fairly stable $(1,6,21,22)$; however, only DMCT remains stable at $100^{\circ} \mathrm{C}$. and highly acid or alkaline $\mathrm{pH}$. Other factors, such as differences in solubility and affinity for certain tissues, including blood plasma, may account for the different distribution, sequestration in certain organs and rates of elimination of these analogues.

Wide differences in the serum half-life of intravenously injected tetracyclines are reported, or can be calculated from data in the literature. The divergences are probably due, in large part, to the methods of assay and to the time allowed for equilibration in the body before the blood samples are drawn. In this laboratory, the twofold dilution method has generally yielded a shorter halflife than the cup-plate method $(2,23)$. Spitzy and Hitzenberger (24), employing a 2:3 serial dilution method for assay, reported the half-life of CTC, TC and OTC in blood following injec- tion of $100 \mathrm{mg}$. to be $2.74,2.04$ and 0.73 hours, respectively. Calculations from data presented by others for TC show the half-life to be 3.0 to 6.6 . hours after doses of 100 to $500 \mathrm{mg}$. (dilution method) (25), 7.5 hours after a $500 \mathrm{mg}$. dose (method unspecified) (26), and about 14 hours after a similar dose (dilution method) (27).

In the present study, in which the more accurate cup-plate method was used, the half-life of each analogue in serum was fairly distinct and was ranked in the same order for each subject. The longest mean half-life was that of DMCT (12.7 and 11.8 hours for the two doses), followed, in order, by those of OTC (9.2 hours), TC (8.5 hours) and CTC (5.6 hours). These values for DMCT and TC correspond to those previously reported after six hours' equilibration following oral doses, viz., 11.8 and 8.2 hours, respectively (2), and are also in agreement with the value of about 10 hours for the serum half-life of DMCT calculated from the data of Sweeney, Hardy, Dornbush and Ruegsegger (3), the same assay method being used in all these studies.

Few reports are available on the relative distribution volume of the tetracycline analogues. Spitzy and Hitzenberger (24) reported the relative distribution volume of TC, CTC and OTC to be 95,92 and 90 per cent of body weight, respectively. The values derived in the present study were considerably higher. OTC was found to have the largest distribution volume, exceeding 180 per cent of body weight in each subject with a mean value of 189 per cent. The $500 \mathrm{mg}$. dose of DMCT gave a mean value of 179 per cent followed by TC, CTC and the $250 \mathrm{mg}$. dose of DMCT at 159, 148 and 148 per cent of body weight, respectively. The reason for the discrepancy between the two DMCT values is not readily apparent, but may be due, in part, to differences in time required for equilibration. In any event, all these results must be interpreted with considerable caution because of $a$ ) the considerable errors involved in the microbiological assays of both the dose injected and the concentrations in the serum, and $b$ ) the error inherent in the single injection method of determining distribution volume due to incomplete or irregular equilibration of drug in body compartments (28). Nevertheless, the gross differences in distribution of OTC, TC and CTC may be important in interpretation 
of data obtained in oral absorption studies in which these three drugs are compared (4). Because of its larger relative distribution volume OTC may be expected to produce lower blood levels than the other two analogues even if it were absorbed equally well. A better method of comparing the completeness of absorption may be the total urinary recovery and this is discussed below.

Although the relative distribution volumes of the tetracycline analogues are very large, the drugs are not evenly distributed throughout the body. Studies of the distribution of OTC and CTC in the tissues of the mouse by means of autofluorescence microscopy have shown the highest concentrations of these drugs to be in the liver, kidney and reticuloendothelial system $(17,18)$. Snell, Gorkuscha and Allen (19), employing C14labeled OTC in mice, found the greatest accumulation of radioactivity in the liver which also tended to retain drug in high concentrations even after the labeled drug could no longer be detected in the blood. Leevy, Zinke and Chey (20) using a similar method in man, also found OTC to be sequestered in the liver and slowly released into the blood. ${ }^{6}$

Apparently the size of the relative distribution volume is of no help in predicting the relative degree or order in which the analogues penetrate into the cerebrospinal fluid. Wood and Kipnis (29) obtained higher spinal fluid levels with TC than with OTC and CTC in man after comparable doses. In general, the penetration of these analogues into the cerebrospinal fluid is rather poor despite the large distribution volumes (30-32). Data on penetration of DMCT are not available. Differences in penetration into the cerebrospinal fluid may be an overriding consideration in the choice of drugs under certain conditions.

The major route of excretion of all of the tetracycline analogues is through the kidneys. The reported urinary recoveries of drug vary considerably, but generally TC and OTC have been

\footnotetext{
6 After submission of this paper it was shown that, following a single intravenous injection, DMCT, like the other three analogues, is concentrated in the liver and excreted in the bile where it is found in concentrations up to 32 times greater than in the simultaneously obtained serum. This would indicate that the higher and better sustained serum levels of DMCT cannot be explained by diminished excretion into the bile (41).
}

recovered in larger amounts than CTC $(26,30$ 36). Sweeney, Hardy, Dornbush and Ruegsegger (3) recovered larger amounts of TC and less of CTC as compared with DMCT in an eight hour collection period after an oral dose. In the present study, the most complete recovery was obtained with OTC (70 per cent) followed, in order, by TC (60 per cent), DMCT (42 per cent) and CTC (18 per cent). These recoveries were in close agreement with the expected recovery of these drugs as calculated from the ratio of the rate of renal clearance to serum clearance (Figure 5).

Sirota and Saltzman (37) reported that CTC was cleared by the kidney at about 35 per cent of a simultaneously performed creatinine clearance and that its clearance rate was not altered by an osmotic diuresis. They inferred from this and from their studies on plasma protein binding that CTC was cleared by glomerular filtration. Similar conclusions can be drawn from the data for the four tetracycline analogues obtained in the present study. The analogue that was most rapidly cleared by the kidney was OTC $(85 \pm 14$ per cent), followed in order, by TC ( $62 \pm 8$ per cent) and by CTC and DMCT, both of which were cleared at essentially the same rate, namely about 30 per cent of a simultaneous creatinine clearance. Variations in the rate of urine flow from 2 to $14 \mathrm{ml}$. per minute did not alter these clearances. These results are also in good agreement with those previously reported in an oral absorption study (2) (TC, 71 per cent and DMCT, 31 per cent of the simultaneous creatinine clearance, respectively).

It is realized that these results are based on observations in a small number of normal subjects and that there were considerable variations in some instances. Conceivably, patients with severe infections might handle these drugs differently (23).

It is reasonable to assume from the data presented on the rate and completeness of excretion of the tetracycline analogues into the urine that OTC would be the most readily and completely excreted of the analogues in the urine of patients with renal disease and TC only slightly less so. DMCT may be expected to be retained longer in the blood of a uremic patient, whereas CTC activity would be rapidly dissipated and very little would appear 
AVERAGE SERUM LEVELS

\section{EXPRESSED AS TETRACYCLINE EQUIVALENTS}

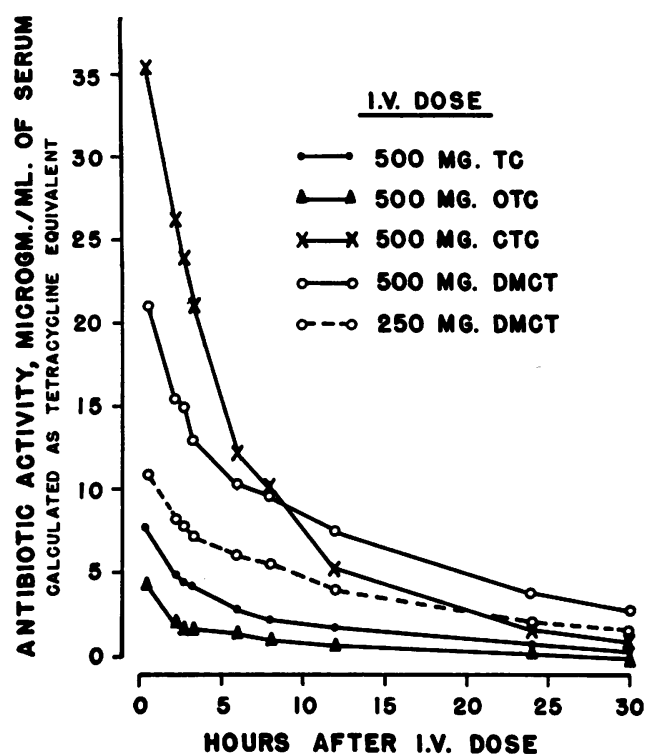

Fig. 6. Average Concentrations of Antibiotic Activity in Serum Resulting from Single Intravenous Doses of Four Tetracycline Antibiotics, All Calculated as Tetracycline Activity and Plotted on an Arith METIC SCALE

in the urine. These expectations are supported in part by calculations of the rate of nonrenal removal of the analogues. Each was found to be removed at about 3 to 4 per cent per hour with the exception of CTC, of which 9.5 per cent was removed per hour by nonrenal mechanisms. Thus, despite the fact that CTC and DMCT are cleared by the kidney at about the same rate, the serum half-life of CTC is about one-half that of DMCT and less than one-half as much is recovered in the urine.

The data pertaining to the rate of nonrenal removal of TC is somewhat at variance with those reported in an earlier study on the persistence of $\mathrm{TC}$ in the blood of anuric patients (23). In that study TC was removed from the serum of anuric patients at a rate of 0.6 to 1.2 per cent per hour as compared with a mean rate of 3.3 per cent per hour calculated in the present study. These differences may be due to $a$ ) the shorter period of equilibration in the present study, $b$ ) differences between assay by the twofold dilution method and the cup-plate method and $c$ ) differences in the "metabolism" of the drug in normal and uremic patients. On the other hand, there is fairly good agreement between the nonrenal removal rate of 9.5 per cent per hour obtained in the present study for CTC and the corresponding rate of about 6 to 10 per cent per hour in uremic patients in the earlier study (23). ${ }^{7}$

Sirota and Saltzman (37) using a fluorophotometric method of assay and somewhat higher concentrations of antibiotic than those employed here, found 65 to 70 per cent of CTC bound to human plasma proteins (mainly albumin), which is greater than the binding demonstrated here. ${ }^{7}$ In the present study, CTC and DMCT were found to be bound to plasma to a similar extent, namely 41 and 47 per cent, respectively, and to about twice the extent of the binding of OTC and TC (20 and 24 per cent, respectively) ${ }^{8}$

In previous studies from this laboratory $(2,4$, 38-40), dealing with blood levels of related antibiotics that are potentially of clinical interest, emphasis has been placed on the importance of either using a single standard of comparison of activity or of comparing the activity of the serums against a variety of test organisms. In the present study, the value for the concentration of each antibiotic in serum and urine was expressed in terms of its own standard since interest here was focused primarily on comparative distribution in the body and relative rates of absorption and excretion which are adequately reflected in this manner. From the clinical point of view, however, comparisons of relative activity of serum or other body fluids at different times after comparable doses are important, and these are best obtained by calculating the levels from the same reference standard.

Such a comparison for the average levels in serum after the single intravenous doses of the four tetracycline analogues is shown in Figure 6, in which tetracycline is used as the standard of

\footnotetext{
7 The difference may represent bound antibiotic that is fluorescent but not antimicrobially active.

8 Wozniak (42), in more thorough dialysis equilibrium studies under physiological conditions of temperature and $\mathrm{pH}$, found that the degree of binding by dog and human plasma for drug concentrations ranging from 1 to $10 \mu \mathrm{g}$. per $\mathrm{ml}$. was approximately twice as much for CTC (6? per cent) as for TC (34 per cent) and was intermediate (49 per cent) for DMCT. She also demonstrated that the binding of tetracycline increased with increasing alkalinity over the $\mathrm{pH}$ range of 6.7 to 8.1 .
} 
reference and the levels of activity are plotted on an arithmetic scale. Similar relationships would be revealed with the use of any of the other three analogues as a standard of reference, except that the absolute values would be altered depending on which of the drugs was used. The considerably greater levels of activity produced in serum by DMCT as compared with either TC or OTC are readily apparent in this figure. Indeed, the 250 mg. dose of DMCT yielded greater activity throughout the period of observation than the 500 mg. dose of either TC or OTC. CTC, on the other hand, produced much greater activity than the same dose of DMCT during the first eight hours, after which the levels from the latter were greater.

It is to be borne in mind, in addition, that these relationships also vary with the test organism. 'Thus, against the strain of Staphylococcus aureus ATCC 6539P used in the turbidimetric assay of the intravenous preparations that were administered, DMCT was about 90 per cent as active as CTC, three times as active as TC and 1.9 times as active as OTC. Against the test strain of $B$. cereus used in the assays of the serums, DMCT was 70 per cent as active as CTC, three times as active as TC and four times as active as OTC.

\section{SUMMARY AND CONCLUSIONS}

The distribution and excretion of the four tetracycline analogues-tetracycline (TC), oxytetracycline (OTC), chlortetracycline (CTC) and demethylchlortetracycline (DMCT)-were studied following single intravenous injections in four healthy young men. Each drug was given in a dose of $500 \mathrm{mg}$. and an additional dose of $250 \mathrm{mg}$. of DMCT was also studied. Estimations of the binding of these analogues to plasma proteins was determined by equilibrium dialysis in vitro.

The mean half-life in serum was longest for DMCT, shortest for CTC and intermediate for TC and OTC.

The greatest mean relative volume of distribution was that of OTC, but all four analogues were distributed through a relative volume greater than the total body weight, indicating that there is considerable sequestration in body compartments, notably the liver.

DMCT was cleared from serum, on the average, about one-half as rapidly as CTC; TC and OTC were cleared at similar rates which were intermediate.

The renal clearances of DMCT and CTC were similar and averaged about 30 per cent of the simultaneous clearance of creatinine; the corresponding values for TC and OTC were 62 and 85 per cent, respectively. The renal clearance rates were not significantly affected by changes in urine flow from 2 to $14 \mathrm{ml}$. per minute. All of these drugs are probably cleared by glomerular filtration.

The average 96 hour urinary recovery of OTC was 70 per cent of the administered dose, as compared with 60 per cent for TC, 42 per cent for DMCT and only 18 per cent for CTC. 'These values corresponded closely to those calculated from the ratio of renal clearance to serum clearance. The greatest proportion of the total of each drug excreted in the urine was recovered in the first 24 hours.

The nonrenal removal rates of TC, OTC and DMCT were very similar and averaged 3 to 4 per cent per hour; CTC, however, was removed much more rapidly by nonrenal mechanisms (9.5 per cent per hour).

Both DMCT and CTC were bound to plasma to about the same extent ( 41 and 47 per cent, respectively) and to about twice the extent of OTC and TC (20 and 24 per cent, respectively), but there were wide variations in these results.

Of the four analogues, therefore, DMCT clearly produces the most sustained levels in the blood, OTC is the most completely excreted in the urine, TC produces slightly less sustained levels in the blood and slightly lower urinary recoveries than OTC, and CTC yields the least sustained levels in blood and the smallest recovery in the urine.

The importance of using a single standard of reference in comparing activity of related drugs was discussed and illustrated by the levels obtained in the serums in the present study.

\section{REFERENCES}

1. McCormick, J. R. D., Sjolander, N. O., Hirsch, U., Jensen, E. R., and Doershuk, A. P. A new family of antibiotics: The demethyltetracyclines. J. Amer. chem. Soc. 1957, 79, 4561.

2. Kunin, C. M., and Finland, M. Demethylchlortetracycline: A new tetracycline antibiotic that yields 
greater and more sustained antibacterial activity. New Engl. J. Med. 1958, 259, 999.

3. Sweeney, W. M., Hardy, S. M., Dornbush, A. C., and Ruegsegger, J. M. Demethylchlortetracycline. A clinical comparison of a new antibiotic compound with chlortetracycline and tetracycline. Antibiot. and Chemother. 1959, 9, 13.

4. Hirsch, H. A., and Finland, M. Antibacterial activity of serum of normal subjects after oral doses of demethylchlortetracycline, chlortetracycline and oxytetracycline. New Engl. J. Med. 1959, 260, 1099.

5. Hirsch, H. A., Wilcox, C., and Finland, M. Comparative in vitro activity of four tetracyclines against common pathogenic bacteria. In preparation.

6. Bohonos, N., Dornbush, A. C., Feldman, L. I., Martin, J. H., Pelcak, E., and Williams, J. H. In vitro studies with chlortetracycline, oxytetracycline and tetracycline. Antibiot. Ann. 1953-1954, p. 49.

7. Kiser, J. S., de Mello, G. C., Eve, V., Lindh, H., Malone, L., Popken, F., Schurr, A., and Waters, M. K. A comparative evaluation of chlortetracycline, oxytetracycline and tetracycline in experimental infections. Antibiot. Ann. 1953-1954, p. 56.

8. English, A. R., P'an, S. Y., McBride, T. J., Gardocki, J. F., Van Halsema, G., and Wright, W. A. Tetracycline-microbiologic, pharmacologic and clinical evaluation. Antibiot. Ann. 1953-1954, p. 70.

9. Minieri, P. P., Firman, M. C., Mistretta, A. G., Abbey, A., Bricker, C. E., Rigler, N. E., and Sokol, H. A new broad spectrum antibiotic product of the tetracycline group. Antibiot. Ann. 1953-1954, p. 81.

10. Love, B. D., Jr., Wright, S. S., Purcell, E. M., Mou, T. W., and Finland, M. Antibacterial action of tetracycline: Comparisons with oxytetracycline and chlortetracycline. Proc. Soc. exp. Biol. (N. Y.) 1954, 85, 25.

11. Welch, H., Randall, W. A., Reedy, R. J., and Oswald, E. J. Variations in antimicrobial activity of tetracyclines. Antibiot. and Chemother. 1954, 4, 741.

12. Eisenberg, G. M., Foltz, E. L., Palazollo, A. J., and Flippin, H. F. Laboratory and clinical observations on tetracycline. Antibiot. Ann. 1954-1955, p. 611.

13. Grove, D. C., and Randall, W. A. Assay Methods of Antibiotics: A Laboratory Manual. New York, Medical Encyclopedia, Inc., 1955, p. 50.

14. Bonsnes, R. W., and Taussky, H. H. On the colorimetric determination of creatinine in the Jaffé reaction. J. biol. Chem. 1945, 158, 581.

15. Smith, H. W. Principles of Renal Physiology. New York, Oxford University Press, 1956.

16. Snedecor, G. W. Statistical Methods Applied to Experiments in Agriculture and Biology. Ames, Iowa, State College Press, 1956.
17. Helander, S., and Böttiger, L. E. On the distribution of Terramycin in different tissues. Acta med. scand. 1953, 147, 71.

18. Böttiger, L. E. On the distribution of chlortetracycline in the body. Acta med. scand. 1955, 151, 343.

19. Snell, J. F., Gorkuscha, R., and Allen, E. L. Radioactive oxytetracycline. II. Distribution in C-57 BL mice (preliminary experiments). Antibiot. Ann. 1957-1958, p. 502.

20. Leevy, C. M., Zinke, M. R., and Chey, W. Y. Observations on the distribution of $\mathrm{C}^{\mathbf{1 4}}$ oxytetracycline in man. Antibiot. Ann. 1958-1959, p. 258.

21. Paine, T. F., Jr., Collins, H. S., and Finland, M. Bacteriologic studies on Aureomycin. J. Bact. 1948, 56, 489.

22. Bliss, E. A., Warth, P. T., Chandler, C. A., and Long, P. H. Studies of Terramycin, in vivo and in vitro. Bull. Johns Hopk. Hosp. 1950, 87, 171.

23. Kunin, C. M., Rees, S. B., Merrill, J. P., and Finland, M. The persistence of antibiotics in the blood of patients with acute renal failure. I. Tetracycline and chlortetracycline. J. clin. Invest. 1959; 38, 1487.

24. Spitzy, K. H., and Hitzenberger, G. The distribution volume of some antibiotics. Antibiot. Ann. 1957-1958, p. 996.

25. Kent, B., Yow, E. M., and Townsend, E. The concentration of tetracycline in the serum following. parenteral administration. J. Lab. clin. Med. 1956, 47, 203.

26. Maynard, A., Andriola, J. C., and Prigot, A. Tetracycline hydrochloride studies on absorption, diffusion, excretion and clinical trial. Antibiot. Ann. 1953-1954, p. 102.

27. Waddington, W. S., Bergy, G. G., Nielsen, R. L., and Kirby, W. M. M. Tetracycline: Clinical and pharmacologic studies. Amer. J. med. Sci. 1954, 228, 164.

28. Schachter, D., Freinkel, N., and Schwartz, I. L. Movement of inulin between plasma and interstitial fluid. Amer. J. Physiol. 1950, 160, 532.

29. Wood, W. S., and Kipnis, G. P. The concentrations of tetracycline, chlortetracycline and oxytetracycline in the cerebrospinal fluid after intravenous administration. Antibiot. Ann. 1953-1954, p. 98.

30. Herrell, W. F., and Heilman, F. R. Aureomycin: Studies on absorption, diffusion and excretion. Proc. Mayo Clin. 1949, 24, 157.

31. Herrell, W. F., Heilman, F. R., Wellman, W. E., and Bartholomew, L. C. Terramycin: Some pharmacologic and clinical observations. Proc. Mayo Clin. 1950, 25, 183.

32. Werner, C. A., Knight, V., and McDermott, W. Absorption and excretion of Terramycin in humans: Comparison with Aureomycin and chloramphenicol. Proc. Soc. exp. Biol. (N. Y.) 1950, 74, 261.

33. Purcell, E. M., Wright, S. S., Mou, T. W., and Finland, M. Blood levels and urinary excretion in 
normal subjects after ingestion of tetracycline analogues. Proc. Soc. exp. Biol. (N. Y.) 1954, 85, 61.

34. Welch, H., Hendricks, F. O., Price, C. W., and Randall, W. A. Comparative studies on Terramycin and Aureomycin: Antibacterial spectrum, serum concentrations and urinary excretion. J. Amer. pharm. Ass., Sci. ed. 1950, 39, 185.

35. Gocke, T. M., Wells, E. B., Collins, H. S., and Finland, M. Blood levels and urinary excretion of Aureomycin after intravenous and intramuscular administration. J. Lab. clin. Med. 1950, 36, 100.

36. Frisk, A. R., and Tunevall, G. Absorption and excretion of Aureomycin. Scand. J. clin. Lab. Invest. $1950,2,26$.

37. Sirota, J. H., and Saltzman, A. The renal clearance and plasma protein binding of Aureomycin in man. J. Pharmacol. exp. Ther. 1950, 100, 210.
38. Jones, W. F., Jr., and Finland, M. Blood levels from orally administered penicillins $G$ and $V$ : Relation to food intake. New Engl. J. Med. 1955, 253, 754.

39. Hirsch, H. A., Kunin, C. M., and Finland, M. Antibacterial activity of serum of normal men after oral doses of erythromycin propionate and triacetyloleandomycin. New Engl. J. Med. 1959, $260,408$.

40. Hirsch, H. A., and Finland, M. Effect of food on the absorption of erythromycin propionate, erythromycin stearate and triacetyloleandomycin. Amer. J. med. Sci. 1959, 237, 693.

41. Kunin, C. M., and Finland, M. Excretion of demethylchlortetracycline into the bile. New Engl. J. Med. In press.

42. Wozniak, L. A. Studies of the binding of tetracycline by plasma proteins. Antibiot. Ann. 1959-1960. To be published. 